\title{
Knowledge on Rabies Among Homeowners in a Selected Subdivision in Iloilo Province
}

\author{
Mae O. Dahildahil \\ Cantryll T. Javellosa \\ Maria Asuncion S. Jumagbas \\ Stephen M. Montealto \\ Ryan Michael F. Oducado
}

\begin{abstract}
This study aimed to determine the level of knowledge on the nature, cause, signs and symptoms, transmission, prevention, and control of rabies among homeowners, in a chosen subdivision in lloilo Province. It also sought to determine whether or not significant differences occur in their level of knowledge when the homeowners were classified according to age, educational attainment, family income, and number of dogs owned. Conducted last December 2006, this study involved 111 randomly chosen homeowners of Florvel Homes Subdivision, Buray, Oton, Iloilo. Data were gathered through a researcher-made questionnaire-checklist. To describe the data gathered, the means and standard deviations were employed. The t-test for Independent Samples and the One-way Analysis of Variance (ANOVA), both set at 0.05 level of significance, were utilized for inferential analysis. The findings revealed that generally, the homeowners in Florvel Homes Subdivision were highly knowledgeable on the nature, cause, signs and symptoms, prevention, and control of rabies. No significant differences existed in the level of knowledge on rabies among the homeowners classified according to age, educational attainment, family income, and number of dogs owned.
\end{abstract}

An Abstract of an Undergradaute Thesis for the Bachelor of Science in Nursing degree, College of Nursing, West Visayas State University, Iloilo City 